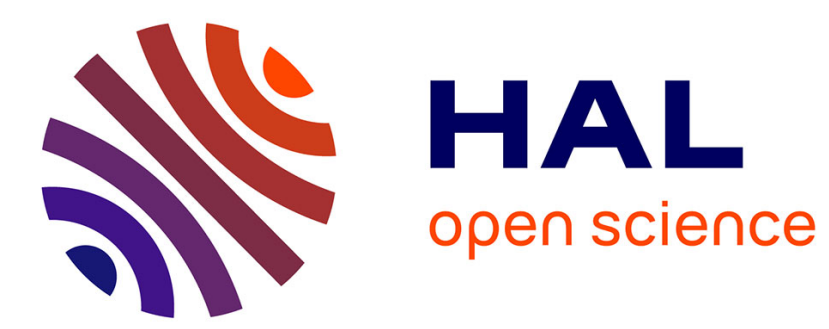

\title{
UHV CHEMICAL VAPOUR DEPOSITION OF UNDOPED AND IN-SITU DOPED POLYSILICON FILMS
}

W. Ahmed, R. Pilkington, D. Meakin

\section{- To cite this version:}

W. Ahmed, R. Pilkington, D. Meakin. UHV CHEMICAL VAPOUR DEPOSITION OF UNDOPED AND IN-SITU DOPED POLYSILICON FILMS. Journal de Physique IV Proceedings, 1991, 02 (C2), pp.C2-809-C2-816. 10.1051/jp4:1991295 . jpa-00249887

\section{HAL Id: jpa-00249887 https://hal.science/jpa-00249887}

Submitted on 1 Jan 1991

HAL is a multi-disciplinary open access archive for the deposit and dissemination of scientific research documents, whether they are published or not. The documents may come from teaching and research institutions in France or abroad, or from public or private research centers.
L'archive ouverte pluridisciplinaire HAL, est destinée au dépôt et à la diffusion de documents scientifiques de niveau recherche, publiés ou non, émanant des établissements d'enseignement et de recherche français ou étrangers, des laboratoires publics ou privés. 
Colloque C2, suppl. au Journal de Physique II, Vol. 1, septembre 1991

\title{
UHV CHEMICAL VAPOUR DEPOSITION OF UNDOPED AND IN-SITU DOPED POLYSILICON FILMS* $(1)$
}

\author{
W. AHMED*, R.D. PILKINGTON* ${ }^{*}$ and D.B. MEAKIN*** \\ "VAPOURGERM Ltd, Phoenix Business Park, Phoenix Close, \\ Heywood, GB-Lancashire OL10 2JG, Great-Britain \\ * Department of Electronic and Eiectrical Engineering, \\ University of Salford, GB-Salford M5 4WT, Great-Britain \\ *** LEYBOLD AG, Bonner strasse 498/P.0. BOx 510760 , \\ D-5000 Cologne 51, Germany
}

\begin{abstract}
The use of low pressure chemical vapour deposition (LPCVD) for the growth of thin films of polysilicon is widely used in integrated circuit fabrication processes. For several emerging technologies, chiefly large-area displays and multilayer memories, the crystalline quality of the as-deposited film is of paramount importance, as the polysilicon is the active semiconductor layer. It is important, in these applications, to lower the deposition temperature to avoid damage either to the substrate or circuit elements already present. The dependence of film morphology on the deposition rate, gas flow rate and reactor temperature is discussed. A reduction in pressure from typical LPCVD pressures (around 200 mTorr) causes the transition temperature to be lowered, allowing a crystalline film to be grown at relatively low temperatures. To achieve this, a special UHVCVD system has been constructed to investigate layer growth at pressures down to $0.2 \mathrm{mTorr}$. Details of work carried out on the growth of insitu phosphorous doped polysilicon are discussed. Uniform phosphorous doped polysilicon films are grown without the need for wafer cages and/or complex gas injectors. At deposition temperatures in the region of $630^{\circ} \mathrm{C}$ and reactor pressures of less than $5 \mathrm{~m}$ Torr uniform doped polysilicon can be deposited. The resistivity and dopant concentrations can be controlled by altering the phosphine-to-silane gas flow ratio.
\end{abstract}

\section{INTRODUCTION}

The low pressure chemical vapour deposition (LPCVD) of thin film polysilicon is a process now used extensively by semiconductor manufacturers [1]. The growth parameters are chosen to optimise the reactor throughput i.e. high deposition rates and uniformity over a large number of substrates [2], as the morphology of the as-deposited film is not of primary importance. For several new technologies, for example large-area displays and multilayer memories, the crystalline quality of the as-deposited layer is of paramount importance as the material is the active semiconductor layer. It is also important to lower the deposition temperature to avoid damage to the substrate or circuit elements already present [3].

The standard industrial approach to the doping of polysilicon involves either post deposition ion implantation or post deposition thermal diffusion. These processes have major disadvantages. Ion implantation requires the use of expensive equipment, while thermal diffusion requires elevated temperatures $\left(\mathrm{ca} 900^{\circ} \mathrm{C}\right.$ ) which can result in the undesirable diffusion of existing dopants.

The use of low pressure chemical vapour deposition (LPCVD) for the production of in-situ doped polysilicon is an attractive process. Doping and deposition are achieved in one simple low temperature

(1) The work was carried out at :

GEC Research Ltd, Hirst Research Centre, East Lane, Wembley, Middlesex HA9 7PP, Great Britain 
step [4]. However, detailed research into the LPCVD of in-situ phosphorous doped polysilicon reveals two major problems; poor within-wafer uniformity $( \pm 60 \%)$ and very low deposition rates $(<10 \AA / \mathrm{min})[5]$. It has been found that the problem of poor uniformity can be overcome by the use of complex quartz wafer cages but for each set of process parameters a newly designed wafer cage is required, this can be difficult and expensive.

In this paper we report work carried out on the growth of as-deposited polysilicon films, in the temperature range $580^{\circ}-630^{\circ} \mathrm{C}$, and in-situ phosphorous doped polysilicon, using a novel ultra low pressure chemical vapour deposition (UHVCVD) system ( 5 mTorr).

\section{EXPERIMENTAL}

The UHVCVD reactor used for this work is shown in figure 1. A fused silica reactor tube was heated by a conventional 3-zone furnace using resistance heaters, giving process temperature uniformity to within

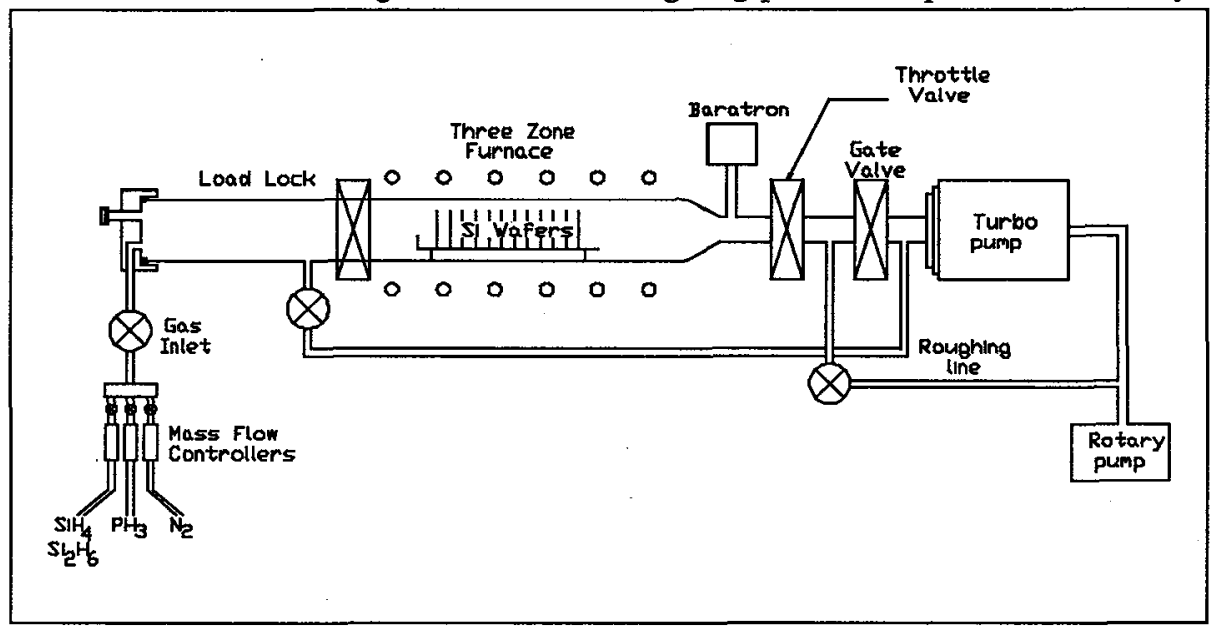

Figure 1 Schematic of UHVCVD system

$\pm 1^{\circ} \mathrm{C}$. For the ultra low pressure experiments a turbomolecular pump backed by a 2-stage rotary pump was used, which were isolated from the main system by a gate valve and throttle valve for independent pressure control. The process pressure was measured by a $51 / 2$ digit capacitance manometer (MKS) with an accuracy of better than $1 \%$ in the pressure range 0.2 to $200 \mathrm{~m}$ Torr and zeroed prior to each deposition by pumping to less than $10^{-6}$ Torr. A quadrupole mass spectrometer was used to check the quality of vacuum and to analyse the process gas composition. The process gas (100\% silane) was admitted to the chamber via a gas handling system including a low-flow (0-5 sccm) mass flow controller. Precision electronics and a controlled environment were used to ensure stability and reproducibility of flow.

For the as-deposited experiments $75 \mathrm{~mm}$ diameter thermally oxidised silicon wafers were used and the system was pumped with the turbomolecular pump for thirty minutes to allow the wafer temperature to stabilise. At this point the base pressure, without baking the stainless steel vacuum lines, was less than $10^{-6}$ Torr. Silane was admitted to the chamber at the desired flow rate and the throttle valve activated to obtain the correct process pressure. In the case of deposition at $200 \mathrm{mTorr}$, a changeover to a Roots pump was effected and the pressure controlled by a throttle valve in the Roots pump line. Films in the thickness 
range 0.2 to 1.5 microns were grown, which covered both the thickness range used in TFT's (around 0.3 microns) and also allowed inspection of thicker films to elucidate effects observed in thinner films. Polysilicon films were grown in the temperature range $580-630^{\circ} \mathrm{C}$ with the silane flow rates of 0.5 to 5.0 $\mathrm{sccm}$ and pressures ranging from 0.2 to $180 \mathrm{~m}$ Torr.

For the in-situ doped experiments the furnace temperature was set at $630^{\circ} \mathrm{C}$.with a flat profile. Depositions were carried out on $50 \mathrm{~mm}$ and $75 \mathrm{~mm}$ diameter thermally oxidised silicon. $50 \mathrm{~mm}$ silicon was used to allow comparison with earlier work on in-situ doped polysilicon, carried out under standard LPCVD conditions i.e. $675^{\circ} \mathrm{C}$ and $200 \mathrm{~m}$ Torr. Again, the system was pumped for thirty minutes to allow the wafer temperature to stabilise. Silane and phosphine were admitted to the chamber at the desired flow rates and the throttle valve activated to obtain the correct process pressure. In the case of deposition at $180 \mathrm{~m}$ Torr, a changeover to a Roots pump was effected and the pressure controlled by a throttle valve in the Roots pump line.

After deposition, the chamber was evacuated to less than $10^{-6}$ Torr and backfilled with inert gas prior to removal of the test wafers. Thicknesses were measured with a surface profilometer and an optical thickness monitor. The resistivity and phosphorous content of the in-situ doped films were measured using a 4-point probe and electron microprobe analysis.

\section{RESULTS AND DISCUSSION}

\section{As-deposited polysilicon - Deposition rate and uniformity}

Figure 2 shows the growth rate as a function of the total pressure at $630^{\circ} \mathrm{C}$ with silane flow rates of 1 and $5 \mathrm{sccm}$. It can be seen that the deposition rate is unaffected by the total system pressure under these conditions. Several workers have suggested that under typical LPCVD conditions the

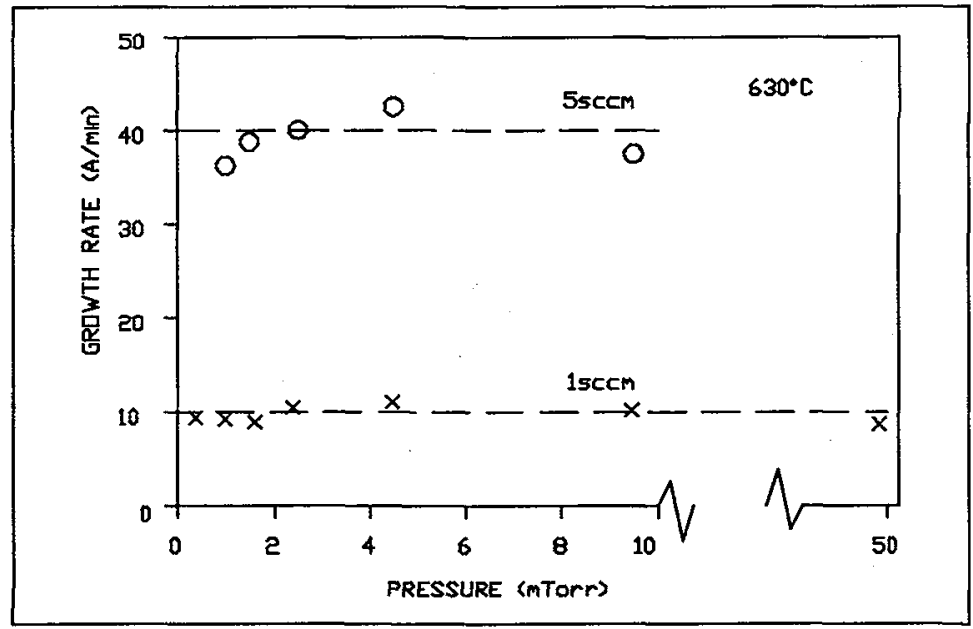

Figure 2 Growth rate Vs Pressure

silane decomposes into $\mathrm{SiH}_{2}$ in the gas phase and may recombine with silane to form disilane $\left(\mathrm{Si}_{2} \mathrm{H}_{6}\right)$. In our investigations, residual gas analysis using a quadrupole mass spectrometer, showed that no disilane 
was present in the gas phase. Moreover, the radial uniformity on the wafers was better than $0.5 \%$.

Figure 3 shows the deposition rate as a function of wafer position for gas flows of 1 and 5 sccm and a system pressure of $5 \mathrm{~m}$ Torr. For both gas flows the deposition rate decreased from wafer 1 to wafer 25 by a factor of two, due primarily to the depletion of silane along the length of the reactor tube. However, at flow rates of $5 \mathrm{sccm}$ the deposition rate is 4-5 times greater than that obtained at $1 \mathrm{sccm}$.

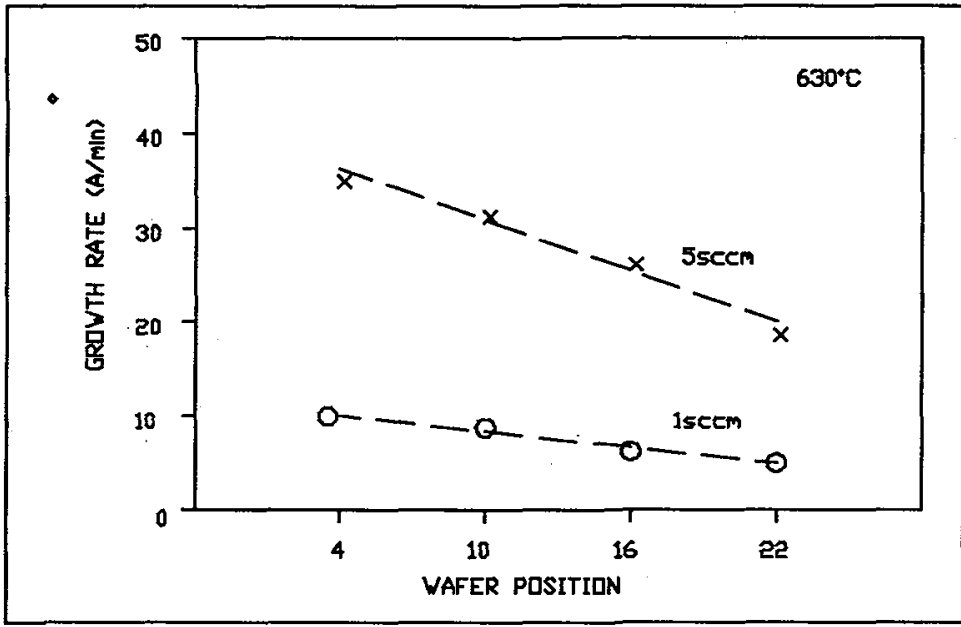

Figure 3 Deposition rate as a function of wafer position

For standard LPCVD conditions the deposition rate has been observed to increase linearly with low flow rate and then saturate at higher flow rates [6]. At low rates the surface of the wafers is deficient of silane with many active sites available for silane (or its products) adsorption. As the flow rate is increased these sites become filled and eventually saturate.

The temperature dependence of the deposition rate for the zeroed wafer position is shown in Figure 4. At $150 \mathrm{mTorr}$, the apparent activation energy is calculated to be $50 \mathrm{kcal} / \mathrm{mol}$. This is in agreement with Donahue and Reif [7] who investigated the effect of system pressure on activation energy and found it to be independant of pressure. However, as the pressure is reduced the kinetic to mass transport transition temperature is lowered. When the system pressure was lowered to $40 \mathrm{mT}$ Torr, by reducing the silane gas flow rate form $60 \mathrm{sccm}$ to $12 \mathrm{sccm}$, the apparent activation energy was calculated to be $38 \mathrm{kcal} / \mathrm{mol}$. At this low flow rate it is concluded that the reduction of the activation energy is not due to a change in the rate determining surface process but an artifact of the reduced supply of silane precursor to the surface. For the deposition rate to increase with temperature, more silane must be supplied to the surface. It has been shown that for a cold wall single wafer reactor in the temperature range of $600-675^{\circ} \mathrm{C}$ the activation energy is independent of pressure [7]. 


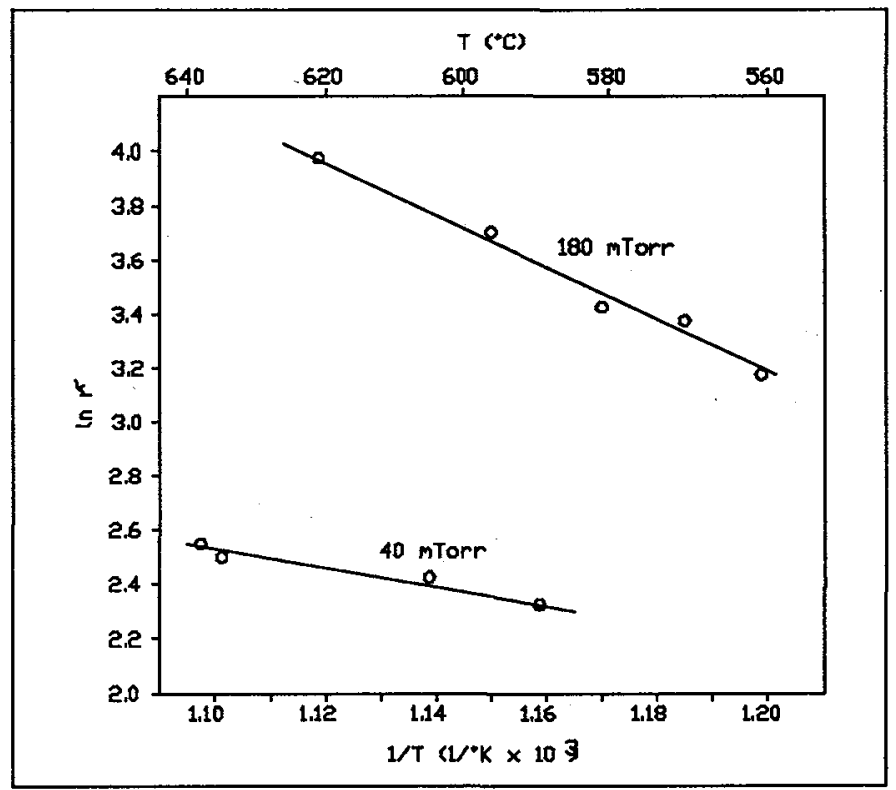

Figure 4 Deposition rate Vs temperature

\section{In-situ doped polysilicon - Deposition rate and uniformity}

Figure 5 shows the variation in radial thickness a films grown at 1.5 mTorr and gas flow rates of 5 sccm for silane and $1 \mathrm{sccm}$ for $1 \%$ phosphine in nitrogen. Under these conditions highly uniform doped films are obtained, in contrast to those deposited at $180 \mathrm{~m}$ Torr [8,9]. For all gas flow ratios employed excellent film thickness uniformity was observed for pressures less than $5 \mathrm{~m}$ Torr. A noticeable deterioration of the film uniformity results when pressure is increased while keeping the gas flow ratios constant. At 180 $\mathrm{m}$ Torr the uniformity matched those previously reported. Repeating this experimênt using $75 \mathrm{~mm}$ diameter wafers resulted in a similar trend. However, at a reactor pressure of 180 mTorr the uniformity of thickness was much improved when compared with the $50 \mathrm{~mm}$ wafers. A similar effect has been observed in semiinsulating polysilicon (SIPOS) [10].

The deposition rate as a function of the phosphine to silane ratio at a reactor pressure of $2.5 \mathrm{mTorr}$ is shown in figure 6. Results are comparable to those obtained at standard LPCVD pressures [11]. It is concluded that the fundamental reaction kinetics, under these conditions, are similar to those at standard LPCVD pressures. The dopant phosphine molecule and its surface reaction product phosphorous, adsorb very strongly to the wafer surface blocking silane adsorption. This prevents silane decomposition which results in low deposition rates [12,13]. Mass spectral analysis of the residual gases confirms that there is an increase in the silane concentration in the exhaust gases.

The improvement in the uniformity may be explained by two separate mechanisms. Firstly, the addition of phosphene to the gas phase suppresses the heterogeneous reactions of silane and promotes the homogeneous gas phase reactions. This gives rise to reactive products such as silylene and disilane which are highly reactive and quickly deplete as they travel from the annular region of the reactor to the wafer 


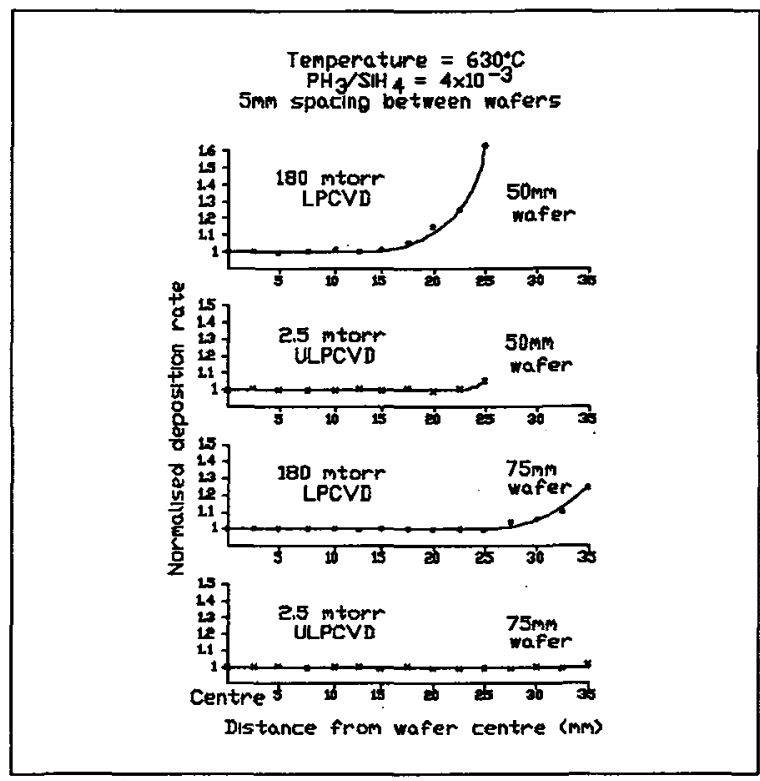

Figure 5 Variations in radial thickness

surface, giving rise to non-uniformity within wafers [11]. By operating at sufficiently low pressures, such as those employed in ULPCVD, the homogeneous reactions of silane decrease linearly, silicon deposition is therefore primarily from the silane precursor. Secondly, gas diffusion increases with decreased pressure. At the pressures used in the ULPCVD reactor, the diffusivity of gas species is increased by a factor of a hundred. Thus even if silane intermediates are present, uniform deposition can be expected.

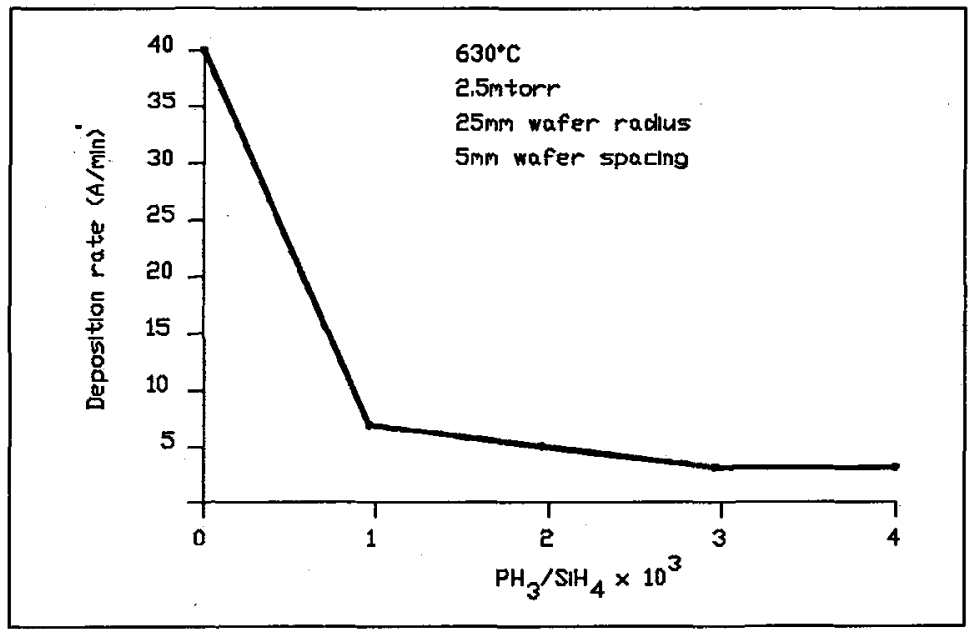

Figure 6 Deposition rate $\mathrm{Vs}_{\mathrm{PH}}: \mathrm{SiH}_{4}$ ratio 
Resistivity

For as-deposited films $\left(630^{\circ} \mathrm{C}\right.$ and 1.5 mTorr) the resistivities were found to be $7.8 \times 10^{-2} \Omega \mathrm{cm}$ and $2.7 \mathrm{x}$ $10^{-2} \Omega \mathrm{cm}$, for phosphine-to-silane ratios of $1 \times 10^{-3}$ and $2 \times 10^{-3}$ respectively.

Annealing in nitrogen at $900^{\circ} \mathrm{C}$ lowered the resistivities to $6.75 \times 10^{-3} \Omega \mathrm{cm}$ and $4.68 \times 10^{-3} \Omega \mathrm{cm}$ respectively. This reduction in resistivity may be understood by using the general model for polycrystalline films [14]. With prolonged annealing the resistivity reaches a critical value (minimum)

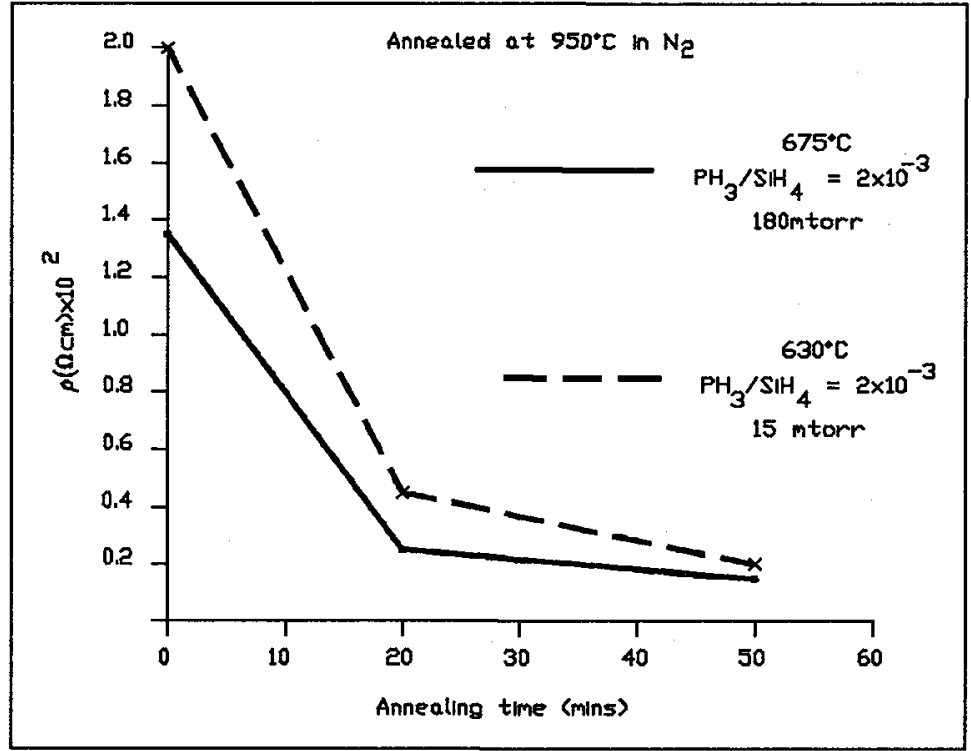

Figure 7 Resistivity Vs annealing time

corresponding to a maximum crystallite size. Figure 7 shows the change in resistivity of in-situ doped polysilicon films with annealing time. The unannealed films grown by LPCVD (grown at $675^{\circ} \mathrm{C}$ ) show lower resistivity values than those grown by ULPCVD (grown at $630^{\circ} \mathrm{C}$ ). The initial deposition temperature affects the grain size of the film, as the temperature increases so does the grain size [15]. The larger the grain size the greater the $\mathrm{P}_{\mathrm{A}} / \mathrm{P}_{\mathrm{T}}$ ratio, giving rise to the lower resistivity. With long annealing times, the resistivities of films grown by both LPCVD and ULPCVD become similar due to grain growth saturation.

The as-deposited in-situ doped films were analysed for their total phosphorous content using electron microprobe. For phosphine-to-silane ratios of $1 \times 10^{-3}$ and $2 \times 10^{-3}$ the total phosphorous content was 6 $\times 10^{19} \mathrm{~cm}^{-3}$ and $8.9 \times 10^{19} \mathrm{~cm}^{-3}$ respectively. Hence it is possible to control both the resistivity and the dopant concentration by varying the phosphene-to-silane flow rate ratio. 


\section{CONCLUSION}

The use of a UHV-CVD reactor has been described giving polycrystalline films The effect of reactor parameters on the deposition rate and film structure has been presented and the properties of these films will allow the fabrication of high quality polysilicon TFT's on glass substrates at considerably lower temperatures than hitherto.

Good uniform in-situ phosphorous doped polysilicon films have been deposited, employing a reactor temperature of $630^{\circ} \mathrm{C}$ and pressures of less than 5 mTorr, without the use of sophisticated quartz wafer cages or a specially designed gas injector system. Under these growth conditions the rate of diffusion of the reactant gases increases which suppresses the silane homogeneous gas chemistry. The change in resistivity of these films with annealing is explained using the general model for film structure and grain growth. At present the growth rates are low, but it is felt that by incorporation of plasma enhancement or the use of a more reactive silicon source, such as disilane, the process could well have an industrial future.

\section{REFERENCES}

1. Rosler R S, Solid State Tech. 20(4) (1977) 63

2. Baudrant A and Sacilotti M, J of Electrochem Soc 129 (1982) 1109

3. Ahmed W, Meakin D B, Stoemenos J, Economou N A and Pilkington R D, J of Mat Sci Accepted for publication (1991)

4. Meyerson B S and Oldbricht W, J of Electrochem Soc 131 (1984) 2365

5. Ahmed W and Meakin D B, J of Cryst Growth 74 (1986) 394

6. Van den Brekel C H J and Bollen L J, J of Cryst Growth 54 (1981) 310

7. Donahue T J and Reif R, J of Electrochem Soc 133 (1986) 1691

8. Hitchman M L and Ahmed W, Vacuum 34 (1984) 979

9. Ahmed W, Phd thesis, University of Salford (1986)

10. Hitchman M L and Kane J, J of Cryst Growth 55 (1981) 485

11. Jensen K F, Hitchman M L and Ahmed W, Proc of EuroCVD 5, Upsala, Sweden (1985) 144

12. Meyerson B S and Yu M L, J of Electrochem Soc 131 (1984) 2366

13. Meyerson B S, Ganin E, Smith D A and Nguyen T N, J of Electrochem Soc 133 (1986) 1232

14. Seto J, J of Electrochem Soc 46 (1975) 4357

15. Kamins T I, Mandurah M M and Saraswat K C, J of Electrochem Soc 125 (1982) 90 